Saudi Journal of Medicine

Abbreviated Key Title: Saudi J Med ISSN 2518-3389 (Print) |ISSN 2518-3397 (Online) Scholars Middle East Publishers, Dubai, United Arab Emirates Journal homepage: https://saudijournals.com

Original Research Article

\title{
Study of Complications and Visual Impairement in Vernal Keratoconjunctivitis (VKC)
}

\author{
Dr. Surekha Bangal ${ }^{1 *}$, Dr. Mahima Bankar ${ }^{2}$, Dr. Akshita Sharma ${ }^{3}$, Dr. Rashi Sharma ${ }^{3}$ \\ ${ }^{1}$ Professor, Departmnt of Ophthalmology, Rural Medical College of Pravara Institute of Medical Sciences, Pravara Institute of Medical Sciences, Loni, \\ Maharashtra 413736, India \\ ${ }^{2}$ Senior Resident, Rural Medical College of Pravara Institute of Medical Sciences, Pravara Institute of Medical Sciences, Loni, Maharashtra 413736, \\ India \\ ${ }^{3}$ Postgraduate Student, Rural Medical College of Pravara Institute of Medical Sciences, Pravara Institute of Medical Sciences, Loni, Maharashtra \\ 413736, India
}

DOI: $10.36348 /$ sjm.2021.v06i01.001 $\quad$ | Received: 14.12.2020| Accepted: 31.12 .2020 | Published: 05.01 .2021

*Corresponding Author: Dr. Surekha Bangal

\section{Abstract}

Aim: To study the complications and visual impairment in vernal keratoconjunctivitis. Method: A prospective hospitalbased study was carried out in 100 VKC patients over a period of 2 years. All patients suffering from VKC irrespective of age and gender were included while patients suffering from ocular infections and ocular trauma were excluded from the study. Ocular complaints, duration of symptoms and previous treatment taken. The ocular examination included visual acuity, slit lamp examination, IOP and refraction. Results: Corneal complications were noted in $21 \%$ of cases followed by lids in $18 \%$ of cases. Corneal complications such as superficial scarring was noted in $11 \%$ followed by micropannus in $4 \%$, pseudogerontoxon in $3 \%$ and shield ulcer in $2 \%$ and keratoconus in $1 \%$. the corneal involvement was seen in 5.5\% in palpebral form, $23.53 \%$ in bulbar, and $48.2 \%$ in mixed pattern of VKC. Thus, it is concluded that maximum corneal involvement is observed in mixed clinical pattern of VKC. Majority of cases (82\%) had visual acuity ranging from 6/6 to 6/9 in right eye as well as left eye. Visual acuity in the form of counting fingers was present in 4 cases. Out of 100 cases, 55\% cases showed refractive errors in the form of astigmatism, myopia and hypermetropia. Astigmatism was found to be commonest refractive error. In our study we observed steroid induced glaucoma in $1 \%$ of cases. Conclusion: VKC is of more concern due to involvement of cornea and its complications like, shield ulcers, superficial corneal scarring, keratoconus, astigmatism, mechanical ptosis. Steroid induced glaucoma although rare but is a serious complication. Visual acuity is affected mainly due to corneal involvement leading to astigmatism, scarring and keratoconus.

Keywords: VKC, complications, visual impairment.

Copyright () 2021 The Author(s): This is an open-access article distributed under the terms of the Creative Commons Attribution 4.0 International License (CC BY-NC 4.0) which permits unrestricted use, distribution, and reproduction in any medium for non-commercial use provided the original author and source are credited.

\section{INTRODUCTION}

Allergic disease as a clinical entity is well known from ancient times. Fifteen percent of world's population suffers from allergic disease. It is estimated that 10 percent to 20 percent of population of India suffers from one or the other allergic disease, of these more than one third have ocular allergic manifestations [1]. The eye is frequent target of inflammation in both local and systemic allergies like allergic rhinitis, atopic dermatitis, and asthma [2]. Allergic conjunctivitis includes the diverse group of diseases; the largest group being associated with exogenous allergens. The four classic forms of allergic conjunctivitis are seasonal allergic conjunctivitis, vernal keratoconjunctivitis, giant papillary conjunctivitis and atopic keratoconjunctivitis. Vernal Keratoconjunctivitis (VKC) was first described by Arlt in 1846 as conjunctivitis lymphatica [3, 4]. It is characterized by chronic, bilateral, recurrent, interstitial, self-limiting allergic inflammation of conjunctiva having a periodic seasonal incidence [3-5]. It is believed to be diseases of childhood; mean age of presentation is 12 years and generally resolves after puberty, usually around $4-10$ years after onset. The disease is more common among males, with the male to female ratio varying from 4:1 to $2: 1$. It is characterized by itching, redness, discomfort, stringy discharge, photophobia, burning and stinging, giant papillae on the upper tarsal conjunctiva, superficial keratopathy, and corneal shield ulcers, keratoconus leading on to permanent corneal damage [6]. The seasonal character of the disease is most striking feature, it starts in May and June and recedes in autumn i.e. the inflammation often goes into remission in cooler months. The immunopathogenesis of $\mathrm{VKC}$ is multifactorial involving a Th2 mediated mechanism with an 
overexpression of cytokines, growth factors; eosinophils and eosinophilic proteins [4]. Patients with VKC have a family history of atopic diseases in $49 \%$ of cases. These patients may also have a medical history of other atopic conditions including asthma (26.7\%), rhinitis (20\%), and eczema $(9.7 \%)$ and showing no evidence of infection [7]. VKC is of more concern due to its vision threatening complications like, keratoconus, corneal scarring, refractive errors, shield ulcers and treatment related complications like steroid induced glaucoma $[6,8]$. This study will reveal most frequently observed complications of vernal keratoconjunctivitis seen in rural population and will help in suggesting measures to prevent complications in this population.

\section{MATERIAL AND METHODS}

A prospective hospital-based cross-sectional study was carried out and 100 patients were selected having any forms/ types of vernal keratoconjunctivitis upto 50 years of age. Patients suffering from ocular infections and ocular trauma were excluded from the study. Predesigned study proforma was used to collect data and history was obtained with special attention to characteristic symptoms, duration of occurrence of symptoms and previous treatment taken was noted. Family history and history of atopic disease was also noted. Visual acuity was recorded using Snellens chart. Slit biomicroscopic examination was performed to evaluate corneal and conjunctival involvement. Anterior segment photographs were taken for pictorial documentation. Intraocular pressure was measured using non-contact tonometer in patients.

\section{RESULTS}

Out of 100 patients with $\mathrm{VKC}$, majority of cases presented in the age group of 10- 15 years followed by age group less than 10 years, with mean age 15.4 years, $\mathrm{SD} \pm 8.11$ years.

Table-1: Age distribution of VKC cases

\begin{tabular}{|c|c|c|c|c|}
\hline \multirow{3}{*}{ Age in years } & \multicolumn{4}{|c|}{ Clinical pattern of VKC } \\
\hline & Palpebral & Bulbar & Mixed & Total cases \\
\hline & No. $(\%)$ & No. $(\%)$ & No. $(\%)$ & No. (\%) \\
\hline$<\mathbf{1 0}$ & $16(29.63 \%)$ & $5(29.41 \%)$ & $9(31.03 \%)$ & $30(30 \%)$ \\
\hline $10-15$ & $17(31.48 \%)$ & $6(35.29 \%)$ & $10(34.48 \%)$ & $33(33 \%)$ \\
\hline 15-20 & $9(16.67 \%)$ & $2(11.76 \%)$ & $3(10.34 \%)$ & $14(14 \%)$ \\
\hline $20-25$ & $6(11.11 \%)$ & $3(17.65 \%)$ & $4(13.79 \%)$ & $13(13 \%)$ \\
\hline 25-30 & $4(7.41 \%)$ & 0 & $1(3.45 \%)$ & $5(5 \%)$ \\
\hline $30-35$ & $2(3.70 \%)$ & 0 & $1(3.45 \%)$ & $3(3 \%)$ \\
\hline $35-40$ & 0 & 0 & $1(3.45 \%)$ & $1(1 \%)$ \\
\hline $40-45$ & 0 & $1(5.88 \%)$ & 0 & $1(1 \%)$ \\
\hline Total & $54(54 \%)$ & $17(17 \%)$ & $29(29 \%)$ & 100 \\
\hline Mean \pm SD & $\begin{array}{c}15.30 \text { Years } \pm \\
7.23 \text { years }\end{array}$ & $\begin{array}{c}\text { 15.65years } \pm \\
7.46 y e a r s\end{array}$ & $\begin{array}{c}\text { 15.46years } \pm \\
\text { 8.22years }\end{array}$ & $\begin{array}{c}\text { 15.40years } \pm \\
\text { 8.11years }\end{array}$ \\
\hline
\end{tabular}

Out of 100 cases with VKC, $68 \%$ were male and $32 \%$ were females, with M: F ratio 2.2:1.

Table-2: Age and Gender in VKC cases

\begin{tabular}{|c|c|c|c|}
\hline Gender & Age $<25$ years & Age $>25$ years & Total cases \\
\hline Male & 63 & 5 & 68 \\
\hline Female & 27 & 5 & 32 \\
\hline Total & 90 & 10 & 100 \\
\hline
\end{tabular}


VKC related complications were seen in 40 cases $(40 \%)$. Out of which corneal scarring (11\%), pseudogerontoxon $(3 \%)$, pannus in $(5 \%)$, shield ulcer
(2\%), keratoconus in (1\%) and steroid induced glaucoma was seen in $(1 \%)$ of cases, wherein patient had used topical steroid for long term.

Table-3: VKC and Complications

\begin{tabular}{|c|c|c|c|c|}
\hline \multirow{2}{*}{ Complications } & \multicolumn{5}{|c|}{ Clinical pattern of VKC } \\
\cline { 2 - 5 } & Palpebral & Bulbar & Mixed & Total \\
\cline { 2 - 5 } & No. (\%) & No. (\%) & No. (\%) & No. (\%) \\
\hline \multicolumn{5}{|c|}{ Corneal complications } \\
\hline Keratoconus & 0 & 0 & $1(7.69 \%)$ & $\mathbf{1 ( 1 \% )}$ \\
\hline Micropannus & 0 & $1(5.88 \%)$ & $3(10.34 \%)$ & $\mathbf{4 ( 4 \% )}$ \\
\hline Pseudogerontoxon & 0 & $1(5.88 \%)$ & $2(6.89 \%)$ & $\mathbf{3 ( 3 \% )}$ \\
\hline Shield ulcer & 0 & 0 & $2(15.38 \%)$ & $\mathbf{2 ( 2 \% )}$ \\
\hline Superficial scarring & $2(3.70 \%)$ & $2(11.26 \%)$ & $7(24.13 \%)$ & $\mathbf{1 1 ( 1 1 \% )}$ \\
\hline \multicolumn{7}{|c|}{ Complications of lids } \\
\hline Mechanical ptosis & $4(7.41 \%)$ & 0 & $7(24.13 \%)$ & $\mathbf{1 1 ( 1 1 \% )}$ \\
\hline Blepharitis & $3(5.55 \%)$ & $2(11.76 \%)$ & $2(6.89 \%)$ & $\mathbf{7 ( 7 \% )}$ \\
\hline \multicolumn{7}{|c|}{ Glaucoma } \\
\hline Steriod induced glaucoma & 0 & 0 & $1(7.69 \%)$ & $\mathbf{1 ( 1 \% )}$ \\
\hline Total & $\mathbf{9 ( 1 6 . 6 6 \% )}$ & $\mathbf{6 ( 3 4 . 7 8 \% )}$ & $\mathbf{2 5}(\mathbf{9 4 . 1 4 \% )}$ & $\mathbf{4 0 ( 4 0 \% )}$ \\
\hline
\end{tabular}

It was seen that the corneal involvement was seen in $5.5 \%$ in palpebral form, $23.53 \%$ in bulbar, and $48.2 \%$ in mixed pattern of VKC. Thus, it is concluded that maximum corneal involvement is observed in mixed clinical pattern of VKC.

Table-4: Corneal involvement and VKC

\begin{tabular}{|c|c|c|c|c|}
\hline \multirow{2}{*}{ Corneal involvement } & \multicolumn{4}{|c|}{ Clinical pattern of VKC } \\
\cline { 2 - 5 } & Palpebral & Bulbar & Mixed & Total \\
\cline { 2 - 5 } & No. (\%) & No. (\%) & No. (\%) & No. (\%) \\
\hline Yes & $3(5.5 \%)$ & $4(23.53 \%)$ & $14(48.2 \%)$ & $\mathbf{2 1 ( 2 1 \% )}$ \\
\hline No & $51(94.4 \%)$ & $13(76.47 \%)$ & $15(51.7 \%)$ & $\mathbf{7 9}(79 \%)$ \\
\hline Total & $\mathbf{5 4 ( 5 4 \% )}$ & $\mathbf{1 7}(17 \%)$ & $\mathbf{2 9}(29 \%)$ & $\mathbf{1 0 0}$ \\
\hline
\end{tabular}

Majority of cases (24\%) developed VKC related complications with a duration of symptoms from 1 year to 5 years, followed $8 \%$ between 5 years to 10 years. Mechanical ptosis was observed in all groups of duration of disease. 
Table-5: Duration of symptoms and complications of VKC

\begin{tabular}{|c|c|c|c|c|c|}
\hline \multirow{3}{*}{ Complications } & \multicolumn{5}{|c|}{ Duration of symptoms (in years) } \\
\hline & $<1$ year & 1-5 years & 5-10 years & $10-15$ years & $15-20$ years \\
\hline & No. $(\%)$ & No. (\%) & No. (\%) & No. (\%) & No. (\%) \\
\hline \multicolumn{6}{|c|}{ Corneal complications } \\
\hline Keratoconus & 0 & $1(1 \%)$ & 0 & 0 & 0 \\
\hline Micropannus & $1(1 \%)$ & $2(2 \%)$ & $1(1 \%)$ & 0 & 0 \\
\hline Pseudogerontoxon & 0 & $2(2 \%)$ & $1(1 \%)$ & 0 & 0 \\
\hline Shield ulcer & 0 & $1(1 \%)$ & $1(1 \%)$ & 0 & 0 \\
\hline Superficial Corneal scarring & 0 & $8(8 \%)$ & $3(3 \%)$ & 0 & 0 \\
\hline \multicolumn{6}{|c|}{ Complications of lids } \\
\hline Mechanical ptosis & $3(3 \%)$ & $5(5 \%)$ & $1(1 \%)$ & $1(1 \%)$ & $1(1 \%)$ \\
\hline Blepharitis & $1(1 \%)$ & $4(4 \%)$ & $1(1 \%)$ & 0 & $1(1 \%)$ \\
\hline \multicolumn{6}{|c|}{ Glaucoma } \\
\hline Steriod induced glaucoma & 0 & $1(1 \%)$ & 0 & 0 & 0 \\
\hline
\end{tabular}

Majority of cases (82\%) had visual acuity ranging from $6 / 6$ to $6 / 9$ in right eye as well as left eye. Visual acuity in the form of counting fingers was present in 4 cases. Out of 100 cases, 55\% cases showed refractive errors in the form of astigmatism, myopia and hypermetropia. Astigmatism was found to be commonest refractive error.

Table-6: Refractive error and VKC

\begin{tabular}{|c|c|c|c|c|}
\hline \multirow{2}{*}{ Refractive error } & \multicolumn{4}{|c|}{ Clinical pattern of VKC } \\
\cline { 2 - 5 } & Palpebral & Bulbar & Mixed & Total \\
\cline { 2 - 5 } & No. (\%) & No. (\%) & No. (\%) & No. (\%) \\
\hline Emetropia (EMT) & $31(57.41 \%)$ & $8(47.06 \%)$ & $6(20.69 \%)$ & $\mathbf{4 5}(45 \%)$ \\
\hline Astigmatism (AST) & $10(18.52 \%)$ & $7(41.18 \%)$ & $18(62.07 \%)$ & $\mathbf{3 5}(\mathbf{3 5} \%)$ \\
\hline Hypermetropia (HMT) & $2(3.70 \%)$ & $1(5.88 \%)$ & $3(10.35 \%)$ & $\mathbf{6 ( 6 \% )}$ \\
\hline Myopia (MYP) & $11(20.37 \%)$ & $1(5.88 \%)$ & $2(6.89 \%)$ & $\mathbf{1 4 ( 1 4 \% )}$ \\
\hline Total & $\mathbf{5 4 ( 5 4 \% )}$ & $\mathbf{1 7}(\mathbf{1 7} \%)$ & $\mathbf{2 9}(\mathbf{2 9} \%)$ & $\mathbf{1 0 0}$ \\
\hline
\end{tabular}

\section{DISCUSSION}

Vernal Keratoconjunctivitis (VKC) also known as "spring catarrh" is a chronic type of allergic conjunctivitis. In our study as shown in Table-1 we found that $63 \%$ of patients were below 15 Years at the time of presentation and the mean age was 15.4 years, with $\mathrm{SD} \pm 8.11$. Hence it is more common in children and young adults. In our study, male predominance was noted with $68 \%$ males as compared to $32 \%$ females. M: F ratio was 2.2: 1. Similar observations were made by the most authors except Chenge et al., [8] and Ukponmwam et al., [9] in their studies.

Corneal complications were noted in $21 \%$ of cases followed by lids in $18 \%$ of cases. Corneal complications such as superficial scarring was noted in $11 \%$ followed by micropannus in $4 \%$, pseudogerontoxon in $3 \%$ and shield ulcer in $2 \%$ and keratoconus in $1 \%$. It was seen that the corneal involvement was seen in $5.5 \%$ in palpebral form, 
$23.53 \%$ in bulbar, and $48.2 \%$ in mixed pattern of VKC. Thus it is concluded that maximum corneal involvement is observed in mixed clinical pattern of VKC. Our results about superficial scarring are similar with the study of Ujwala S Saboo et al., [9] and Tabbara et al., who found $11 \%$ and $12 \%$ of cases with superficial scarring respectively [10]. Ujwala S Saboo et al., in their study found shield ulcer in $3 \%$ of cases. Hence our study matches with this study [9].

We found lid complications such as mechanical ptosis in $11 \%$ and blepharitis in $7 \%$ of cases. In a study by Ujwala $\mathrm{S}$ Saboo et al., mechanical ptosis was seen in $1.6 \%$ of cases [9]. Bonini et al., in their study reported mechanical ptosis in $5.1 \%$ of cases [11].

In our study we observed steroid induced glaucoma in $1 \%$ of case. Similar results were observed by Saleh et al., in their study with $0.69 \%$ of cases of steroid induced glaucoma [12]. Bonini et al., found steroid induced glaucoma in $2.1 \%$ of cases [11].

$82 \%$ cases had visual acuity ranging from $6 / 6$ to $6 / 9$ in right eye as well as left eye. Visual acuity in form of counting fingers was present in 2 cases of corneal scarring and keratoconus respectively each in right and left eye. Out of 100 cases of VKC, 45 cases did not show any refractive error. Among remaining 55 ametropic patients, 35(63.6\%) cases had astigmatism followed by $14(25.4 \%)$ cases with myopia and 6 $(10.9 \%)$ cases with hypermetropia.

Mean IOP was $15.74 \pm 1.98$ and $15.06 \pm 1.86$ respectively in right and left eyes of the patients. One patient was found with glaucomatous disc changes in fundus and had IOP $25 \mathrm{mmHg}$ in right eye and 22 $\mathrm{mmHg}$ in left eye and was under topical antiglaucoma medication.

\section{CONCLUSION}

VKC is of more concern due to involvement of cornea and its complications like, shield ulcers, superficial corneal scarring, keratoconus, astigmatism, mechanical ptosis. Steroid induced glaucoma although rare but is a serious complication. Visual acuity is affected mainly due to corneal involvement leading to astigmatism, scarring and keratoconus.

\section{REFERENCES}

1. Steven, B. K. ocular immunology in health and diseases, chapter 4, ocular allergic response, 93.

2. Pediatric ophthalmology and strabismus book, section 6, 2010-2011, chapter 16 infectious and allergic ocular diseases, 197.

3. Bielory, L., \& Friedlaender, M. H. (2008). Allergic conjunctivitis. Immunology and allergy clinics of North America, 28(1), 43-58.

4. Steward, D. E. Allergic conjunctivitis. System of ophthalmology. 8 part 1: 432:493.

5. Zicari, A. M., Nebbioso, M., Lollobrigida, V., Bardanzellu, F., Celani, C., Occasi, F., ... \& Duse, M. (2013). Vernal keratoconjunctivitis: atopy and autoimmunity. Eur Rev Med Pharmacol Sci, 17(10), 1419-1423.

6. Kumar, S. (2009). Vernal keratoconjunctivitis: a major review. Acta ophthalmologica, 87(2), 133147.

7. Bonini, S., Bonini, S., Lambiase, A., Marchi, S., Pasqualetti, P., Zuccaro, O., ... \& Bucci, M. G. (2000). Vernal keratoconjunctivitis revisited: a case series of 195 patients with long-term followup. Ophthalmology, 107(6), 1157-1163.

8. Kumar, S. (2009). Vernal keratoconjunctivitis: a major review. Acta ophthalmologica, 87(2), 133147.

9. Chenge, B., Makumyamviri, A. M., Kaimbo, W. A., \& Kaimbo, D. (2003). Tropical endemic limbo-conjunctivitis in Lúbumbashi, Democratic Republic of the Congo. Bulletin de la Societe belge d'ophtalmologie, (290), 9-16.

10. Saboo, U. S., Jain, M., Reddy, J. C., \& Sangwan, V. S. (2013). Demographic and clinical profile of vernal keratoconjunctivitis at a tertiary eye care center in India. Indian journal of ophthalmology, 61(9), 486.

11. Tabbara, K. F. (1999). Ocular complications of vernal keratoconjunctivitis. Canadian journal of ophthalmology, 34(2), 88-92.

12. Bonini, S., Bonini, S., Lambiase, A., Marchi, S., Pasqualetti, P., Zuccaro, O., ... \& Bucci, M. G. (2000). Vernal keratoconjunctivitis revisited: a case series of 195 patients with long-term followup. Ophthalmology, 107(6), 1157-1163.

13. Al-Akily, S. A., \& Bamashmus, M. A. (2011). Ocular complications of severe vernal keratoconjunctivitis (VKC) in Yemen. Saudi journal of ophthalmology, 25(3), 291-294. 